\title{
Electronic origin of the anomalous solid solution hardening of $Y$ and Gd in Mg: A first-principles study
}

\author{
GAO Lei ${ }^{1,2}$, ZHOU Jian $^{3}$, SUN ZhiMei $^{3}$, CHEN RongShi $^{1^{*}} \&$ HAN EnHou ${ }^{1}$ \\ ${ }^{1}$ State Key Laboratory for Corrosion and Protection, Institute of Metal Research, Chinese Academy of Sciences, Shenyang 110016, China; \\ ${ }^{2}$ Graduate School of the Chinese Academy of Sciences, Beijing 100049, China; \\ ${ }^{3}$ Department of Materials Science and Engineering, College of Materials, Xiamen University, 361005 Xiamen, China
}

Received January 12, 2010; accepted April 3, 2010

\begin{abstract}
$\mathrm{Y}$ and Gd demonstrate anomalous solid solution hardening efficiency, which cannot be understood using the elastic impuritydislocation interaction theory. We performed first-principles calculations to investigate the effect of different alloying elements such as $\mathrm{Al}, \mathrm{Zn}, \mathrm{Y}$, and $\mathrm{Gd}$ on the chemical bonding of $\mathrm{Mg}$ solid solutions. The present calculations clearly show that the anomalous solid solution hardening of $\mathrm{Y}$ and $\mathrm{Gd}$ in $\mathrm{Mg}$ may be understood based on the increased bonding strength of both $\mathrm{Mg}-\mathrm{Y}(\mathrm{Gd})$ and $\mathrm{Mg}-\mathrm{Mg}$.
\end{abstract}

magnesium alloys, solid solution hardening, first-principles, chemical bonding

Citation: Gao L, Zhou J, Sun Z M, et al. Electronic origin of the anomalous solid solution hardening of Y and Gd in Mg: A first-principles study. Chinese Sci Bull, 2011, 56: 1038-1042, doi: 10.1007/s11434-010-4052-0

As the lightest metallic structural alloy with a good combination of castability, mechanical properties and ductility, magnesium alloys have attracted increasing attention in the automotive and aerospace industries [1]. It has been reported that the addition of rare-earth (RE) elements, such as $\mathrm{Y}, \mathrm{Gd}, \mathrm{Ce}$, and Dy, significantly improves the mechanical properties of $\mathrm{Mg}$ alloys at ambient as well as at elevated temperatures $[2,3]$. The strengthening by the RE elements is more substantial than any other elements that have been added to $\mathrm{Mg}$ alloys [4,5]. One of the most effective strengthening mechanisms of $\mathrm{RE}$ in $\mathrm{Mg}$ is solid solution hardening, essentially of either elastic or electronic origin. The elastic origin has been quantitatively established based on the impurity-dislocation interaction theory by Fleischer [6] and Labusch [7], and is correlated with the atomic size factor $(\delta)$ and/or the modulus misfit parameter $(\eta)$. For a number of alloying elements $(\mathrm{Zn}, \mathrm{Al}, \mathrm{Pb}, \mathrm{Li}, \mathrm{Tl}, \mathrm{Cd}$, In, etc.) in $\mathrm{Mg}$ the efficiency of solid solution hardening increases monotonically with the increase of $|\delta|$ or $|\eta|$, or a

*Corresponding author (email: rongshichen@yahoo.com) combined misfit parameter of them [8,9]. This relation has been verified for aluminium [10], iridium [11], copper [12], nickel [13], and stainless steel [14] solid solution alloys. However, recent experimental studies [4,5,15,16] have demonstrated that $\mathrm{Y}$ and Gd exhibit anomalously higher solid solution hardening efficiency than those of $\mathrm{Al}$ and $\mathrm{Zn}$ in terms of the misfit parameters, which cannot be understood using the elastic interaction model. Such anomalous solid solution hardening of other RE elements, such as $\mathrm{Ce}$ [17] and Dy [18], was also reported. A few experimental and theoretical studies have been carried out to explore the solid solution hardening of RE in Mg. However, the nature of this anomalous behavior has not yet been explained in the literature. Miura et al. [18] evaluated the elastic interaction based on isotropic or anisotropic distortion strains by solute atoms, and it was found that the elastic strain by $\mathrm{Zn}$ atoms is higher than those of $\mathrm{Y}$ and Dy, while the solid solution hardening of basal slip by $\mathrm{Y}$ or Dy addition is much higher than that by $\mathrm{Zn}$ addition. Ninomiya et al. [19] have proposed another solid solution hardening model based on a discrete variational-X $\alpha$ molecular orbital calculation, but 
the details of the solid solution hardening mechanism of $\mathrm{Mg}-\mathrm{RE}$ alloys have not been elucidated yet.

In this paper, we have studied the solid solution hardening from the view point of chemical bonding by means of first-principles calculations based on the density functional theory. The aim of this work is to explain the anomalous solid solution hardening of $\mathrm{Y}$ and $\mathrm{Gd}$ in $\mathrm{Mg}$ from the electronic origin. Our findings are important for the further understanding of the alloying behavior in a simple metal, and are useful for the design of commercial magnesium alloys.

\section{Computational methods}

Magnesium has a hexagonal close-packed (hcp) lattice of space group $P 6_{3} / m m c$ with two atoms in a unit cell. In the present work, $\mathrm{Mg}_{53} \mathrm{X}_{1}$ solid solutions corresponding to a doping concentration of 1.85 at. $\%$ were modeled by a $3 \times 3 \times 3$ supercell of magnesium $\left(\mathrm{Mg}_{54}\right)$, in which one magnesium atom was substituted by a solute atom $\mathrm{X}(\mathrm{X}=\mathrm{Al}$, $\mathrm{Zn}, \mathrm{Y}$, and Gd) at the center site of the supercell. Primary test calculations demonstrated that the results were independent of the doped position. The Vienna Ab initio Simulation Package (VASP) [20] based on the first-principles density functional theory (DFT) was used. The projector augmented-wave pseudo-potentials [21,22] were used to depict the interactions between the valence electrons and the core. The generalized gradient approximations (GGA) in Perdew-Wang-91 (PW91) scheme [23] was adopted for describing the exchange-correlation interactions. An energy cut-off of 1.25 times the maximum potential energy of either $\mathrm{Mg}$ or $\mathrm{X}$ (whichever element has the higher default cut-off energy) as given in their pseudo-potential files was performed. The relaxation convergence for ions and electrons was $1 \times 10^{-6} \mathrm{eV}$. The integration in the Brillouin zone was made using Monkhorst-Pack [24] $5 \times 5 \times 5 k$-points for the hcp supercell model. The convergence according to $k$-points has also been checked and the $k$-points of $5 \times 5 \times 5$ are sufficient to give good results. The atomic arrangements were relaxed using the second-order Methfessel-Paxton technique [25] with a width of $0.2 \mathrm{eV}$. The tetrahedron method with Blöchl corrections [26] was used for the total energy calculation. The partial density of states (PDOS) and electron localization function (ELF) were obtained using the relaxed structure at the equilibrium volume.

\section{Results and discussion}

The calculated lattice parameters $a$ and $c / a$, equilibrium volume $V_{0}$, and cohesive energy $E_{\text {coh }}$ of pure $\mathrm{Mg}$ together with the available experimental data [27-29] and previous calculations [30-32] are shown in Table 1. It is clear that the present calculations agree well with the experimental values and previous calculations, with the difference being less than $3 \%$ for all the results. Figure 1 shows the theoretical equilibrium volume of $\mathrm{Mg}-\mathrm{X}$ solid solutions as a function of solute composition. The values of the atomic size factor $(\delta$ ) for each element can be determined from Figure 1 according to the method developed by King [28], as also shown in Table 1. The calculated atomic size factor of $\mathrm{Al}$ and $\mathrm{Zn}$ are $-12.91 \%$ and $-18.13 \%$, respectively. Reasonable agreement between our calculations and the experimental data of King [28] ( $-13.73 \%$ and $-20.00 \%$, respectively) as well as with earlier calculations by Uesugi [30] on $\mathrm{Al}$ $(-12.40 \%)$ is obtained. The calculated atomic size factor of $\mathrm{Y}$ and Gd are $+15.63 \%$ and $+17.29 \%$, respectively. No experimental or theoretical data of $\delta$ for $\mathrm{Y}$ and $\mathrm{Gd}$ has been reported so far. Noting that the atomic size factor (absolute value) of $\mathrm{Y}$ and $\mathrm{Gd}$ are smaller than that of $\mathrm{Zn}$, which cannot explain the prominent difference in strengthening efficiency between $\mathrm{Mg}-\mathrm{Y}(\mathrm{Gd})$ and $\mathrm{Mg}-\mathrm{Al}(\mathrm{Zn})$ alloys. Therefore, this anomalous solid solution hardening behavior may be due to the specific chemical bonding, as will be discussed in the following section using the $\mathrm{Mg}_{53} \mathrm{X}_{1}$ solid solutions as an example.

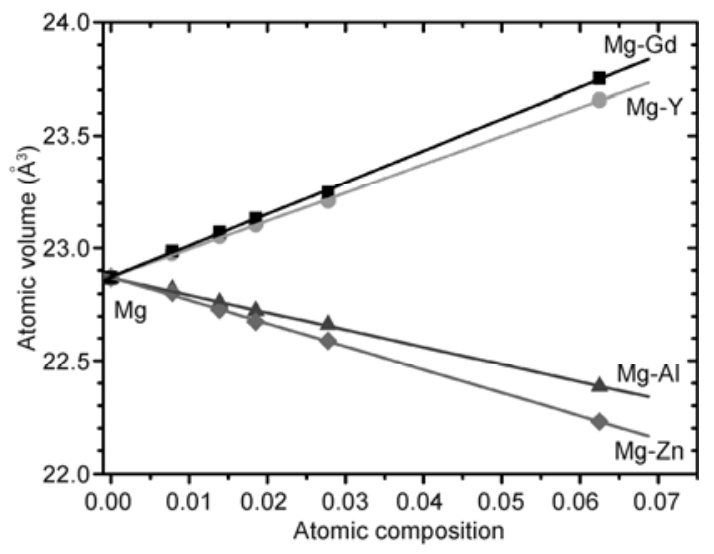

Figure 1 The theoretical equilibrium atomic volume of $\mathrm{Mg}-\mathrm{X}(\mathrm{X}=\mathrm{Al}$, $\mathrm{Zn}, \mathrm{Y}$, and $\mathrm{Gd}$ ) solid solutions as a function of solute composition.

Table 1 The calculated and experimental lattice parameters $a$ and $c / a$, equilibrium atomic volume $V_{0}$, and cohesive energy $E_{\text {coh }}$ of pure $\mathrm{Mg}$, as well as the atomic size factor $\delta$ for $\mathrm{Al}, \mathrm{Zn}, \mathrm{Y}$, and $\mathrm{Gd}$ in $\mathrm{Mg}$ solid solutions, respectively

\begin{tabular}{|c|c|c|c|c|c|c|c|c|}
\hline \multirow{2}{*}{$\mathrm{Mg}$} & \multirow{2}{*}{$a(\AA)$} & \multirow{2}{*}{$c / a$} & \multirow{2}{*}{$V_{0}\left(\AA^{3}\right)$} & \multirow{2}{*}{$E_{\text {coh }}(\mathrm{eV} /$ atom $)$} & \multicolumn{4}{|c|}{$\delta(\%)$} \\
\hline & & & & & $\mathrm{Al}$ & $\mathrm{Zn}$ & $\mathrm{Y}$ & $\mathrm{Gd}$ \\
\hline Calc. [this work] & 3.191 & 1.627 & 22.88 & -1.52 & -12.91 & -18.13 & +15.63 & +17.29 \\
\hline Exp. [27-29] & 3.202 & 1.624 & 23.23 & -1.51 & -13.73 & -20.00 & - & - \\
\hline Calc. [30-32] & 3.193 & 1.622 & 22.86 & -1.48 & -12.40 & - & - & - \\
\hline
\end{tabular}


In order to gain better understanding of the chemical bonding in $\mathrm{Mg}_{53} \mathrm{X}_{1}$, we have calculated the partial density of state (PDOS), which is shown in Figure 2. It is seen that the $s$ - and $p$-electron states of alloying elements are spread in a relatively wide energy range. It is also interesting to note that the PDOS of $\mathrm{Mg}_{53} \mathrm{X}_{1}$ can be divided into two groups,
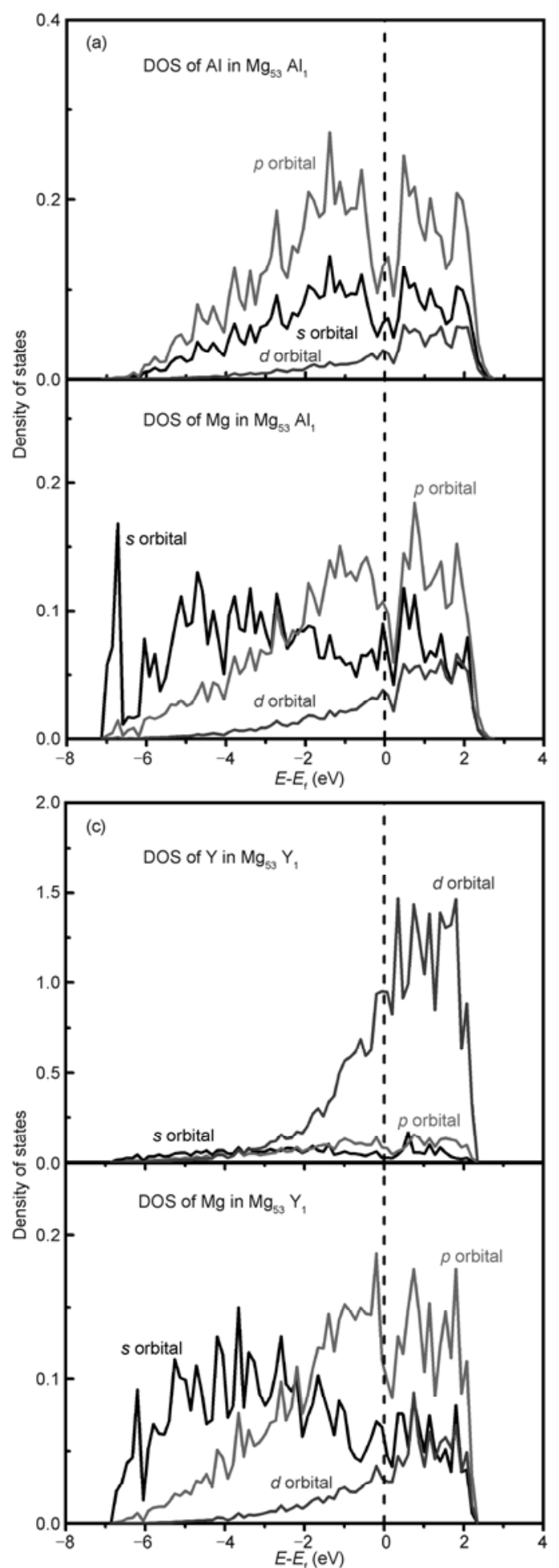

one consisting of $\mathrm{Mg}_{53} \mathrm{Al}_{1}$ and $\mathrm{Mg}_{53} \mathrm{Zn}_{1}$, and the other consisting of $\mathrm{Mg}_{53} \mathrm{Y}_{1}$ and $\mathrm{Mg}_{53} \mathrm{Gd}_{1}$. For $\mathrm{Mg}_{53} \mathrm{Al}_{1}$ and $\mathrm{Mg}_{53} \mathrm{Zn}_{1}$ (Figure 2(a) and (b)), the valence states are dominated by the $p$ states of $\mathrm{Mg}$ and $\mathrm{Al}(\mathrm{Zn})$, while for $\mathrm{Mg}_{53} \mathrm{Y}_{1}$ and $\mathrm{Mg}_{53} \mathrm{Gd}_{1}$ (Figure 2(c) and (d)), the states at the Fermi level as well as the valence bands are predominated by the $d$
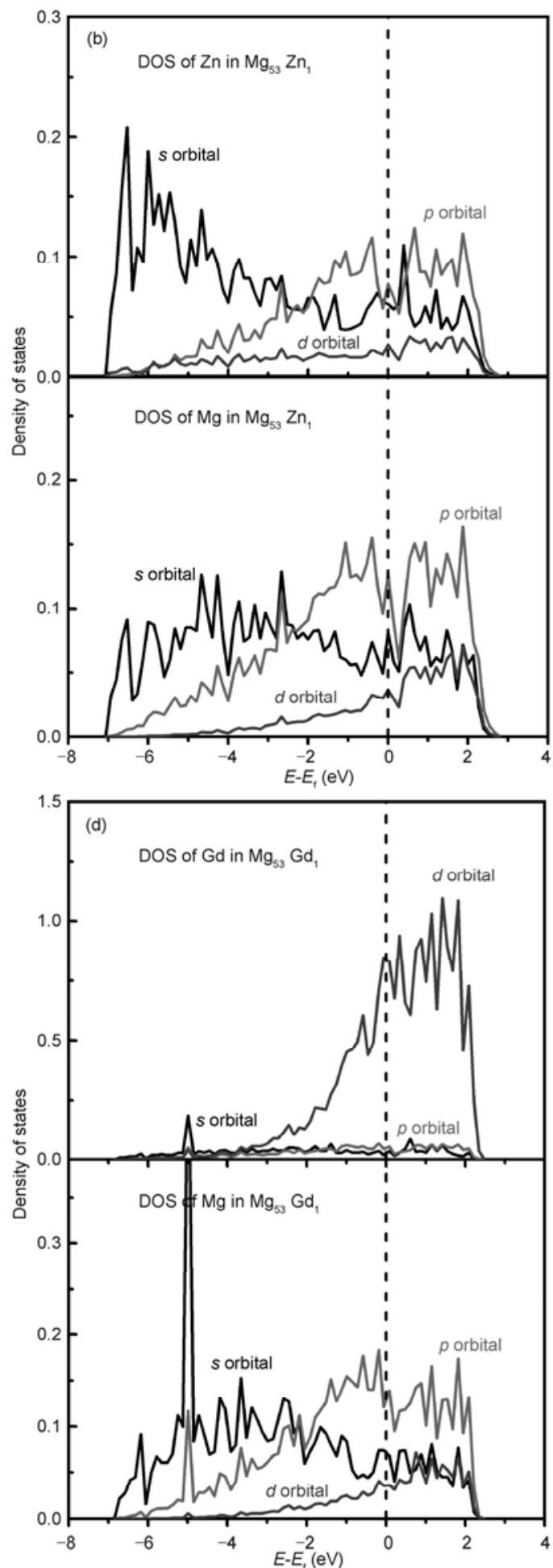

Figure 2 The calculated partial density of states (PDOS) for (a) $\mathrm{Mg}_{53} \mathrm{Al}_{1}$, (b) $\mathrm{Mg}_{53} \mathrm{Zn}_{1}$, (c) $\mathrm{Mg}_{53} \mathrm{Y}_{1}$, and (d) $\mathrm{Mg}_{53} \mathrm{Gd}_{1}$. The Fermi level ( $E_{\mathrm{f}}$ ) is set at zero and marked by a vertical dot line. 
states of $\mathrm{Y}(\mathrm{Gd})$. Strong hybridization between the $p$-orbital of $\mathrm{Mg}$ and the $d$-orbital of Y (Gd) atoms is also observed. This hybridization presents covalent bonding characteristics identified by the electron localization function (ELF) as shown in Figure 3 and plays a major role in the solid solution hardening in $\mathrm{Mg}-\mathrm{Y}(\mathrm{Gd})$ alloys. The results clearly show similar chemical bonding characters between $\mathrm{Mg}_{53} \mathrm{Al}_{1}$ and $\mathrm{Mg}_{53} \mathrm{Zn}_{1}$, and that between $\mathrm{Mg}_{53} \mathrm{Y}_{1}$ and $\mathrm{Mg}_{53} \mathrm{Gd}_{1}$.

$A$ rather quantitative understanding on the chemical bonding of $\mathrm{Mg}_{53} \mathrm{X}_{1}$ solid solutions can be gained by analyzing the electron localization function (ELF). Figure 3 shows the ELF contours in the (0001) plane for $\mathrm{Mg}_{53} \mathrm{X}_{1}$, as well as that of $\mathrm{Mg}_{54}$ for comparison. For $\mathrm{Mg}_{54}$ (Figure 3(a)), a typical metallic bonding feature with ELF of 0.5 (green background) is observed together with weak covalent bonding $(\mathrm{ELF}=0.7)$ between the adjacent $\mathrm{Mg}$ atoms. Significant difference in the chemical bonding caused by the introduction of a solute atom can be observed. Like the above analysis of PDOS, ELF of $\mathrm{Mg}_{53} \mathrm{X}_{1}$ can also be divided into two similar groups. For $\mathrm{Mg}_{53} \mathrm{Al}_{1}$ and $\mathrm{Mg}_{53} \mathrm{Zn}_{1}$
(Figure 3(b) and (c)), electrons at around $\mathrm{Al}(\mathrm{Zn})$ extend to two neighboring $\mathrm{Mg}$ atoms forming quite weak covalent bonds, for example, the $\mathrm{Mg} 1-\mathrm{Al}-\mathrm{Mg} 2$ and $\mathrm{Mg} 1-\mathrm{Zn}-\mathrm{Mg} 2$ covalent bonds, with the later bond being stronger than the former. Furthermore, the introduction of $\mathrm{Al}(\mathrm{Zn})$ results in the increased bonding strength between some neighboring $\mathrm{Mg}$ atoms, for example, between $\mathrm{Mg} 2$ and $\mathrm{Mg} 3$ in Figure 3(b) and (c), which is clearly seen by the large ELF values. For $\mathrm{Mg}_{53} \mathrm{Y}_{1}$ and $\mathrm{Mg}_{53} \mathrm{Gd}_{1}$ (Figure 3(d) and (e)), the covalent interaction among the $\mathrm{Mg}-\mathrm{Y}(\mathrm{Gd})-\mathrm{Mg}$ bonds is much stronger, suggesting the increased bonding strength. This enhanced bonding strength is attributed to the $p$ - $d$ covalent interactions, according to the PDOS analysis (Figure 2(c) and $(d))$. This further indicates that the hybridization of the valence electrons between the $\mathrm{Mg}$ and $\mathrm{Y}(\mathrm{Gd})$ atoms plays a decisive role in solid solution hardening in the $\mathrm{Mg}-\mathrm{Y}(\mathrm{Gd})$ alloy. Furthermore, compared with $\mathrm{Mg}_{54}$, the covalence bonding among some $\mathrm{Mg}$ atoms which are close to $\mathrm{Y}(\mathrm{Gd})$ is also increased, for example, between $\mathrm{Mg} 3$ and $\mathrm{Mg} 4$ in Figure 3(d) and (e), which is not the case in $\mathrm{Mg}_{53} \mathrm{Al}_{1}$ and
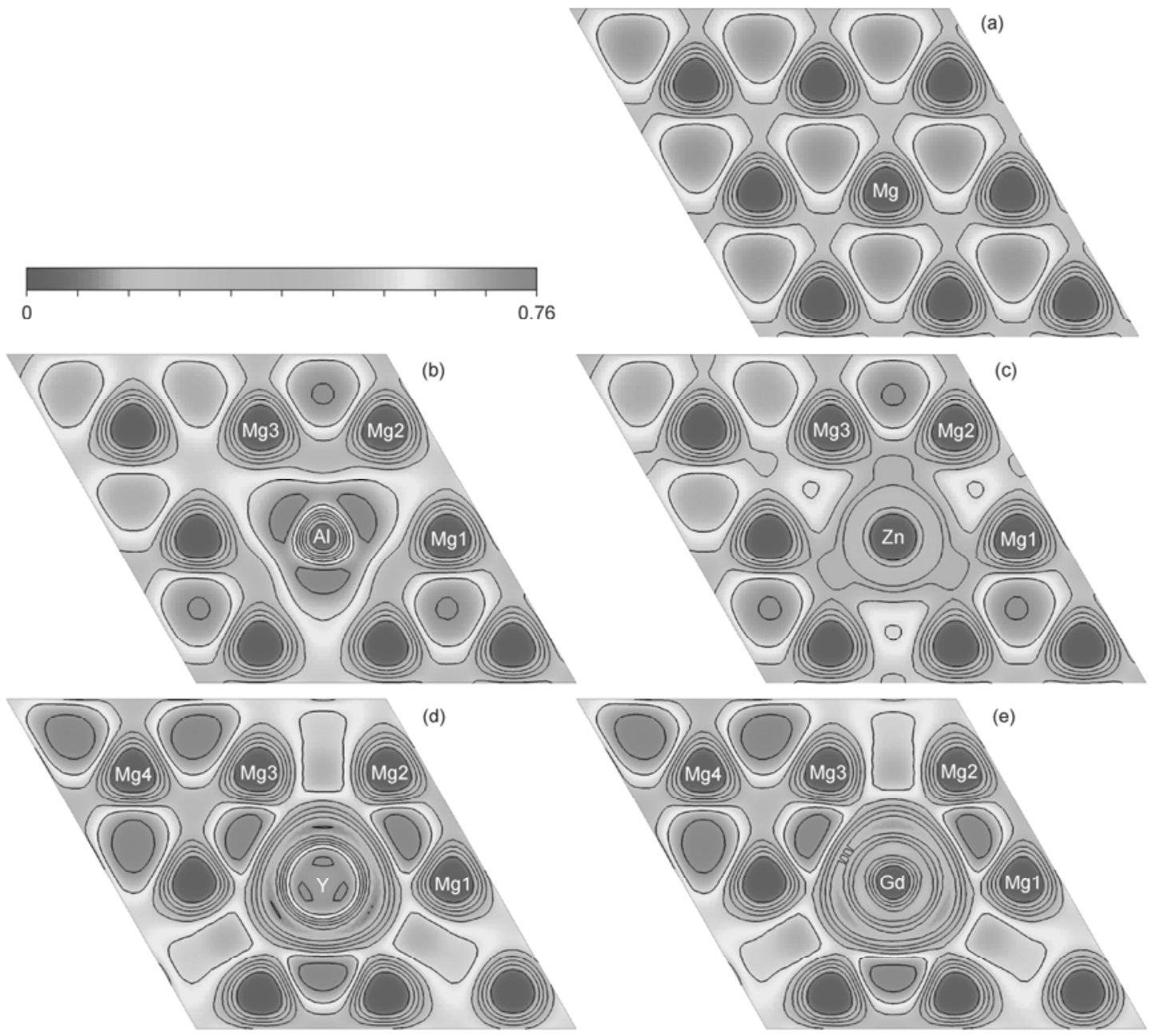

Figure 3 The plot of the electron localization function (ELF) in the (0001) plane of (a) $\mathrm{Mg}_{54}$, (b) $\mathrm{Mg}_{53} \mathrm{Al}_{1}$, (c) $\mathrm{Mg}_{53} \mathrm{Zn}_{1}$, (b) $\mathrm{Mg}_{53} \mathrm{Y}_{1}$ (e) $\mathrm{Mg}_{53} \mathrm{Gd}_{1}$. The $\mathrm{ELF}$ contours range from 0 to 0.76 and increase in steps of 0.1 . 
$\mathrm{Mg}_{53} \mathrm{Zn}_{1}$. Therefore, the substitution of $\mathrm{Y}$ or $\mathrm{Gd}$ in Mg results in significant enhancement in the chemical bonding not only between the $\mathrm{Y}(\mathrm{Gd})$ and $\mathrm{Mg}$ atoms, but also between the $\mathrm{Mg}$ atoms. The covalent bond interactions in the $\mathrm{Mg}-\mathrm{Y}(\mathrm{Gd})$ and $\mathrm{Mg}-\mathrm{Mg}$ bonds are responsible for the anomalously higher solid solution hardening efficiency of RE elements in $\mathrm{Mg}$.

\section{Conclusions}

In summary, we have studied the chemical bonding of $\mathrm{Mg}_{53} \mathrm{X}_{1}$ solid solutions, where $\mathrm{X}=\mathrm{Al}, \mathrm{Zn}, \mathrm{Y}$, and $\mathrm{Gd}$, by means of first-principles calculations. Reasonable agreement between calculated and measured data is observed, thus validating the first-principles methodology employed. The addition of $\mathrm{Y}(\mathrm{Gd})$ to $\mathrm{Mg}$ affects the atomic binding states not only between $\mathrm{Y}(\mathrm{Gd})$ and $\mathrm{Mg}$ atoms, but also between Mg atoms. The mechanism of the anomalous solid solution hardening of RE elements in Mg may be understood based on the increased bonding strength of both $\mathrm{Mg}-\mathrm{Y}(\mathrm{Gd})$ and $\mathrm{Mg}-\mathrm{Mg}$. This suggests the important role of the electronic origin of the solid solution hardening.

Thanks to B.S. Sa and N.H. Miao from Xiamen University for their technical support. The computational resources of Xiamen University are acknowledged. This work was supported by the National Basic Research Program of China (2007CB613704) and National Natural Science Foundation of China (50874100).

1 Mordike B L, Ebert T. Magnesium: Properties-applications-potential. Mater Sci Eng A, 2001, 302: 37-45

2 Gao L, Chen R S, Han E H. Microstructure and strengthening mechanisms of a cast Mg-1.48Gd-1.13Y-0.16Zr (at.\%) alloy. J Mater Sci, 2009, 44: 4443-4454

3 Mordike B L. Creep-resistant magnesium alloys. Mater Sci Eng A, 2002, 324: 103-112

4 Suzuki M, Sato H, Maruyama K, et al. Creep behavior and deformation microstructures of $\mathrm{Mg}-\mathrm{Y}$ alloys at $550 \mathrm{~K}$. Mater Sci Eng A, 1998, 252: 248-255

5 Maruyama K, Suzuki M, Sato H. Creep strength of magnesium-based alloys. Metall Mater Trans A, 2002, 33: 875-882

6 Fleischer R L. Solution hardening. Acta Metall, 1961, 9: 996-1000

7 Labusch R. A statistical theory of solid solution hardening. Phys Stat Sol A, 1970, 41: 659-664

8 Akhtar A, Teghtsoonian E. Substitutional solution hardening of magnesium single crystal. Philos Mag, 1972, 25: 897-916

9 Lukac P. Solid solution hardening in Mg-Cd single crystals. Phys Stat
Sol A, 1963, 131: 377-390

10 Zander J, Sandstrom R, Vitos L. Modelling mechanical properties for non-hardenable aluminium alloys. Comp Mater Sci, 2007, 41: 86-95

11 Yamabe-Mitarai Y, Aoki H. Solid-solution hardening of Ir by Pt and Ni. Mater Lett, 2002, 56: 781-786

12 Čižek L, Kratochvíl P, Smola B. Solid solution hardening of copper crystals. J Mater Sci, 1974, 9: 1517-1520

13 Mishima Y, Ochiai S, Hamao N, et al. Solid solution hardening of nickel: role of transition metal and B-subgroup solute. Trans Jpn Institu Metals, 1986, 27: 656-664

14 Sieurin H, Zander J, Sandstrom R. Modelling solid solution hardening in stainless steels. Mater Sci Eng A, 2006, 415: 66-71

15 Gao L, Chen R S, Han E H. Effects of rare-earth elements Gd and Y on the solid solution strengthening of Mg alloys. J Alloys Compd, 2009, 481: 379-384

16 Gao L, Chen R S, Han E H. Solid solution strengthening behaviors in binary Mg-Y single phase alloys. J Alloys Compd, 2009, 472: 234-240

17 Chino Y, Kado M, Mabuchi M. Compressive deformation behavior at room temperature-773K in $\mathrm{Mg}-0.2$ mass\%(0.035at.\%)Ce alloy. Acta Mater, 2008, 56: 387-394

18 Miura S, Imagawa S, Toyoda T, et al. Effect of rare-earth elements Y and Dy on the deformation behavior of $\mathrm{Mg}$ alloy single crystals. Mater Trans, 2008, 49: 952-956

19 Ninomiya R, Yukawa H, Morinaga M, et al. An electronic approach to the prediction of the mechanical properties of magnesium alloys. $\mathrm{J}$ Alloys Compd, 1994, 215: 315-323

20 Kresse G, Furthmüller J. Efficient iterative schemes for ab initio total-energy calculations using a plane-wave basis set. Phys Rev B, 1996, 54: 11169-11186

21 Blochl P E. Projector augmented-wave method. Phys Rev B, 1994, 50: $17953-17979$

22 Kresse G, Joubert D. From ultrasoft pseudopotentials to the projector augmented-wave method. Phys Rev B, 1999, 59: 1758-1775

23 Perdew J P, Chevary J A, Vosko S H, et al. Atoms, molecules, solids, and surfaces: Applications of the generalized gradient approximation for exchange and correlation. Phys Rev B, 1992, 46: 6671-6687

24 Monkhorst H J, Pack J D. Special points for Brillouin-zone integrations. Phys Rev B, 1976, 13: 5188

25 Methfessel M, Paxton A T. High-precision sampling for Brillouin-zone integration in metals. Phys Rev B, 1989, 40: 3616-3621

26 Blochl P E, Jepsen O, Andersen O K. Improved tetrahedron method for Brillouin-zone integrations. Phys Rev B, 1994, 49: 16223-16233

27 Busk R S. Lattice parameters of magnesium alloys. AIME Trans, 1950, 188: 1460-1464

28 King H W. Quantitative size-factors for metallic solid solutions. J Mater Sci, 1966, 1: 79-90

29 Kittel C. Introduction to Solid State Physics. New York: Wiley, 2005

30 Uesugi T, Kohyama M, Higashi K. Atomic size effects on Al, Ca, and $\mathrm{Sc}$ in $\mathrm{Mg}$ solid solutions from first-principles calculations. Mater Sci Forum, 2003, 426-432: 599-603

31 Wang Y, Curtarolo S, Jiang C, et al. Ab initio lattice stability in comparison with CALPHAD lattice stability. CALPHAD, 2004, 28: 79-90

32 Zhang H, Shang S, Saal J E, et al. Enthalpies of formation of magnesium compounds from first-principles calculations. Intermetallics, 2009, 17: 878-885

Open Access This article is distributed under the terms of the Creative Commons Attribution License which permits any use, distribution, and reproduction in any medium, provided the original author(s) and source are credited. 